\title{
Rhetorical Impact through Hedging Devices in the 'Results and Discussion' Part of a Civil Engineering Research Article
}

\author{
Minoo Khamesian \\ Sanaati Noushirvani University, Iran \\ E-mail: khamesian2006@yahoo.com
}

Doi:10.7575/aiac.alls.v.6n.6p.183

URL: http://dx.doi.org/10.7575/aiac.alls.v.6n.6p.183
Received: 02/08/2015

Accepted: 05/10/2015

\begin{abstract}
It is common knowledge that hedging devices as a rhetorical technique common in all persuasive writing are considerably important in scientific discourse, for they are tools which facilitate presenting claims or arguments in a polite, acceptable and respectful manner. In addition, they are discoursal resources available to a scientific writer's propositions to express uncertainty, skepticism, and open-mindedness.

Research articles are an important means of communication between different members of a discourse community, and will be convincing to a certain extent only when authors are able to employ rhetorical conventions, such as hedging devices, persuasively. However, hedging is a problematic aspect in EAP learning since rarely are the learners able to hedge their statements appropriately, engineering students not being an exception.

Therefore, this article tends to linguistically analyze the function of rhetorical impact of using hedging devices in the results and discussion part of a civil engineering research article published in the Asian Journal of Civil Engineering (Building \& Housing) to conclude that a greater and more systematic attention should be given to hedging devices considering their importance in EAP. The implication is that students, especially the Non Native English Speakers, be taught how to recognize and effectively use hedging devices in their writing as they do not seem to be familiar with hedges and therefore find it particularly difficult to hedge their statements appropriately.
\end{abstract}

Keywords: hedging devices, discourse community, linguostylistic analysis, Civil Engineering Research Articles

\section{Introduction}

It is said time and again that in communicative situations within which a negotiation between the writer and the reader is implied in academic contexts, hedging is generally used as an important rhetorical strategy to mitigate the strength of scientific claims in order to reduce the potential threat that new claims make on other researchers (Meyers, 1989). Hedging is also used to provide researchers with community acceptance for a contribution to disciplinary knowledge by illustrating familiarity with the discourse conventions of a specific academic community (Hyland, 1994, 1998).

In scientific writing the use of hedging devices is of paramount importance for claims to be confirmed by members of any discourse community as they allow scientific writers to present statements with appropriate accuracy, caution and humility. Hedging also helps to negotiate the perspective from which conclusions can be accepted (Hyland, 1996).

Numerous studies show that hedging represents more than one word in every 50, or one hedge in every two or three sentences, although the distribution is explained by the different rhetorical purposes of texts (Skelton, 1988; Hanania and Akhtar, 1985). This is what according to Hyland (1995) is an indication of a level of frequency far higher than many characteristic features of scientific discourse, which traditionally attract much attention in ESP/EAP courses.

According to Hyland (1994) the functions of hedges can be summarized as:

1. Expressing claims with certain degree of caution, modesty and humility.

2. Diplomatic negotiation of the claim when referring to work of colleagues and competitors.

He also maintains that when an author wants to develop his hypothesis into knowledge, he is required to achieve acceptance from the audience. To fulfill the goal, the author needs "linguistic and rhetorical means of persuasion" (Hyland, 1994, p. 435) and this may be the basis for the use of hedging.

Hyland (2008) also maintains that since writers are limited to simply guide readers to a particular interpretation rather than to demonstrate proof, readers are always able to refute their interpretations. Consequently, being persuasive in academic writing means being able to anticipate possible negative reactions to one's claims. To this goal, familiarity with the persuasive practices of the discipline, encoding ideas, employing warrants, and framing arguments in ways that the potential audience will find most convincing is crucial. In this respect, credibility can also be conveyed by establishing a professionally acceptable persona and an appropriate attitude, both to the readers and to the arguments. Briefly speaking, persuasion in academic writing involves using language to relate independent beliefs to shared experience.

Persuasion, then, is accomplished when 'the language we speak with' enables the author to present his viewpoints 
and/or suggest a commentary. Being aware of this will provide the author with recognizing and choosing the rhetorical options available in their fields to appeal to readers from within the boundaries of their disciplines.

\section{Linguostylistic Analysis ${ }^{1}$}

Being a noteworthy rhetorical device in acknowledging the role of readers in the authorization of claims, a better understanding of hedges can provide insights into the interactional nature of academic writing and ways of persuading readers of the author's arguments (Hyland 2005).

Otherwise stated, since EAP register is based on the function of message and calls for 'clarity of purpose' and 'lucidity of exposition', it is believed that, hedges can be of paramount importance in this respect.

Hedging is likely to be used in different rhetorical contexts within a scientific article in order to convey persuasive effect and also to enhance the knowledge claims of the author. In addition, it might set up a strong protective position from which a highly protective position is defended. In this respect, hedging may be realized through various linguistic cues in the Introduction, Result, and Discussion sections, in general, throughout the research paper.

What follows is the linguostylistic analysis of 'discussion \& results' part of a civil engineering research article successfully published in the Asian Journal of Civil Engineering (Building \& Housing), 2011, available at WWW.BHRC.AC.IR/PORTAL/DEFAULT.ASPX?TABID=415, with respect to lexical hedges.

Concentrating on lexical hedges in our work, we classify them into five categories, namely modal verbs, lexical verbs, modal adverbs, modal adjectives, and modal nouns.

As to analyzing the functions of the hedging devices in the text under analysis, we will start with modal verbs as it is believed that linguists have generally been pre-occupied with them. We should hasten to add that the peculiarity encompasses 'may', 'might', 'can', and 'could', with the predominance of 'may', and 'can' over the other two.

In the examples adduced below, it is worth notifying that the modal verb 'may' shows tentativeness and the authors' lack of confidence in the truth of proposition rather than the possibility in terms of natural facts (root may).

It may be related to the less sensitivity of ultrasonic pulse to the changes in hydrated cement paste.

In addition, the drying of cube specimens at $105 \mathrm{oC}$ causes microcracking and may remove some of the combined water resulting in changes in the microstructure of concrete in case of initial surface absorption test.

It may not be a significant quantity to react with entire calcium hydroxide liberated from cement hydration, and thus to maximize the production of secondary hydration products.

Clearly, in all the extracted sentences, the rhetorical function of 'may' seems to refer to toning down the degree of confidence invested in the accuracy of what has been stated. In the following samples the use of 'might' appears to be the same as 'may', just being the past form of it.

Table .... also shows that the crushing value of quarry waste was much higher than that of crushed granite stone and mining sand. Therefore, quarry waste was weaker than mining sand and might contribute to reduce the compressive strength of concrete.

It might cause to reduce the compressive strength of concrete.

As far as the rhetorical impact of using 'can' is concerned, it is worth adding that 'can' is used mostly for the expression of "ability and legitimacy", as the following examples adapted show, i.e. they imply that the deduction arrived at in the study is legitimate.

It can be seen from Figure ... and Figure .... that the ultrasonic pulse velocity of FAQW concrete was lower than that of $C Q W$ and SFQW concretes in both curing methods.

The variation of ultrasonic pulse velocity with compressive strength can be seen in Figure .....

The overall findings of the initial surface absorption test reinforce that the incorporation of quarry waste into flowing concretes demotes the quality of concrete, which can be compensated using an efficient mineral admixture such as silica fume.

As far as 'could' is concerned in the following examples, it is used as an alternative to express possibility with a high degree of tentativeness, helping the author to invest his utterances with the degree of tentativeness he finds suitable. E.g.

In case of fly ash, the pozzolanic reaction mostly occurs at later stage of hydration. But it could not take place since the concrete specimens became dry.

Conversely, fly ash could not produce any significant improvement in ultrasonic pulse velocity.

Turning to the concept of 'lexical verbs', we should hasten to add that they are used to perform such acts as doubting and evaluating rather than describing. There may often be an even more common exponent than auxiliaries. As in our text, they are more frequent than auxiliaries with the prevalence of 'indicate', and 'observe' over the others present in our text, i.e. 'imply'; 'suggest', and 'tend'. Lexical verbs, in our text, characteristically occurred as markers of tentativeness in reports of the author's own work and also indicated the limits to accuracy or applicability of the presented information. In many cases, they appeared in the sentences with inanimate subjects, such as findings, data or results:

It indicates that the porosity of cover concrete was increased in presence of quarry waste. 
It is obvious from Figure ..... that the variation was similar to that observed in case of dynamic modulus of elasticity and compressive strength.

It indicates that the variation was identical for both test conditions.

Similar findings were observed in a previous research of Zain et al.

It indicates that the porosity of cover concrete was increased in presence of quarry waste.

Indubitably, verbs like "indicate" carry less subjective connotations than cognition verbs such as think, believe and suspect. They are also more easily combined with inanimate subjects.

We further continue with the category of modal adverbs. According to Hyland (2008) this category can be concentrated on disjuncts as "down toners" (e.g. usually, slightly, almost, etc.), which are able to lower the force of the verb they modify, with the higher frequency of "slightly", such as the following examples in our analysis:

However, the rate of increase in ultrasonic pulse velocity was identical in both curing methods, as the trendlines had almost the same slope.

Also, the slope of the trendlines indicates that rate of increase in dynamic modulus of elasticity was slightly higher in case of water curing.

It was observed that the air content of CQW concrete was slightly higher than that of control concrete. Further discussion on flowability and air content of the concretes is beyond the scope of the present paper.

And, "style" and "content" disjuncts, the former (e.g. generally, in general, etc,) conveying that "a generalization is being made", and the latter (e.g. likely, apparently, perhaps, etc.) conveying "comment on the truth-value of what is said."

The modulus of elasticity of aggregates is generally higher than that of hydrated cement paste.

The reasons are probably the same, as discussed in case of compressive strength.

This is perhaps due to the reason that the surface zone of the concrete cubes was dealt for initial surface absorption whereas both dynamic modulus of elasticity and ultrasonic pulse velocity were determined using the central zone of concrete cylinders.

We should hasten to add that what all modal adverbs, as hedging devices, have in common is being used to express degrees of tentativeness between the absolutes of 'true' and 'false', i.e. the information presented applies, although conclusive statements cannot be made.

As far as modal adjectives are concerned, we should hasten to add that they are less frequent than the modals analyzed so far. However, what follows is the one, namely "partial" used in the article under analysis.

These values were even higher than those of OPC (control) concrete, thus giving an indication that the inclusion of $20 \%$ quarry waste as a partial replacement of sand did not affect the flowability of the concretes.

In this respect, it is worth adding that this category comprises the items that may be found "when the language user for one reason or another - does not want to indicate the precise extent to which the information applies" (Varttala, 2001). However, the part under analysis is almost devoid of this category.

As Varttala (2001) points out, adjectives expressing probability or marking the information as uncertain or tentative are closely connected to modal adverbs and some sentences with modal adverbs can be paraphrased with structures involving corresponding adjectives. The context in which the modal adjectives are found is quite similar to those of adverbs, however, as mentioned this category is almost absent in our analysis.

Last but not least, as far as modal nouns are concerned, they all share a component of tentativeness and represent that what has been said should not be taken categorically and is based on subjective view or limited knowledge (indication, observation).

These values were even higher than those of OPC (control) concrete, thus giving an indication that the inclusion of $20 \%$ quarry waste as a partial replacement of sand did not affect the flowability of the concretes.

\section{Conclusion}

The linguostylistic analysis of the research article reveals that, rhetorically hedges in scientific writing indicate the author's anticipation of the possibility of opposition to his statements. As a consequence, writing for science can be considered a blend of facts and evaluation since the author attempts to present information as fully, accurately and objectively as possible.

Science tends to concern generalizations rather than individualization, resulting in allocating greater weights to the methods, procedures and equipment used rather than the argument. Modals are able to both reinforce the impersonal view of science and to allow scientists to see themselves as discovering truth rather than constructing it (Hyland, 2009).

Hedges here also tend to assist the author to avoid personal responsibility for his statements in order for his reputation to be protected as scholar and to restrain the likely damage resulting from errors. This is associated with Lakoff's ${ }^{2}$ perspective who considers hedges as similar to "fuzziness" (Hyland 1998), but in this case, hedges were used to blur the relationship between the subjects and their propositions when referring to tentative possibilities.

Last but not least, we should hasten to add that in our analysis hedges contributed to the development of the writer- 
reader relationship, i.e. to address the need for deference and cooperation in gaining reader approval of the author's claims. This is in line with Hyland (1998:35) who maintains, "hedges appeal to readers as intelligent colleague, capable of deciding the issues, and indicate that statements are provisional, pending acceptance by one's peers."

Suffice to say, hedges have an important role in a form of discourse featurised by uncertainty and frequent reinterpretation of how natural phenomena are understood. Hedging is also of paramount importance to scientific writers due to the widely held belief that, even the most assured propositions have an inherently limited period of acceptance which makes the categorical assertions of truth decidedly hazardous.

Considering the importance of hedging devices in academic writing, there might be "a need for greater and more systematic attention to be given to this important interpersonal strategy" (Hyland, 1994, p.244). This implies that the students must be taught how to recognize and effectively use hedging devices in their writing, especially for Non Native English Writers who are probably not familiar with hedges, and therefore, find it particularly difficult to hedge their statements appropriately. In other words, EAP learners will not be able to participate fully and successfully in the world of academic research unless they are familiar with the appropriate use of hedges.

\section{References}

Hanania, E. A. S., \& Akhtar, K. (1985). Verb form and Rhetorical Function in Science Writing. A Study of MS Theses in Biology, Chemistry and Physic. English for Specific Purposes, 4, 49-58.

Hyland, K. (1994). Hedging in Academic Writing and EAP Textbooks. English for Specific Purposes, 13, $239-256$.

Hyland K., (1995). The Author in the Text: Hedging Scientific Writing. Hong Kong Papers in Linguistics and Language, 18.

Hyland, K., (1995). Hedging in Scientific Research Articles. Amsterdam, Philadelphia: John Benjamins Publishing Company.

Hyland, K. (2005). Prudence, Precision, and Politeness: Hedges in Academic Writing. Quaderns de Filologia. Estudis Lingüistics, 5, 99-112.

Hyland, K. (2008). Persuasion, Interaction and the Construction of Knowledge: Representing Self and others in Research Writing. Institute of Education. University of London.

Hyland, K. (2009). Writing in the Disciplines: Research Evidence for Specificity. Taiwan International ESP Journal, $1(1), 5-22$.

Myers, G. (1989). The pragmatic of politeness in scientific articles. Applied Linguistics, 10,1- 35.

Skelton, J. (1988). Comments in academic articles. Grunwell, P. (Ed.), Applied linguistics in society, London: CILT/BAAL, 98-108.

Varttala, T. (2001). Hedging in Scientifically Oriented Discourse: Exploring Variation According to Discipline and Intended Audience. Electronic Dissertationhttp://acta.uta.fa.

\section{Notes}

1. The method of linguostylistic analysis includes the semantic and the metasemiotic levels. On the semantic level linguistic units are regarded as such, as part of the emic system of language. In other words, understanding the general linguistic content, or nominative (direct) meanings of linguistic units is the point. However, this will be a preliminary linguistic investigation from which to pass on to the metasemiotic, or stylistic analysis proper. On this level the focus is on linguistic elements which have become more or less expressive due to certain connotative overtones. The method of linguostylistic analysis is such a universal method that can be applied to all kinds of texts, irrespective of register. Intellective texts which, by definition, aim at passing on pure information can also be subjected to the mentioned analysis. As is shown by scholars, scientific texts, apart from semantic utterances, may also contain a certain amount of metasemiotic utterances and are therefore analyzable in terms of both levels (Gasparyan \& Knyazian 2002).

2. See Lakoff, G. Hedges: A Study in Meaning Criteria and the Logic of Fuzzy Concepts//Journal of Philosophical Logic, 1973, vol. 2, 458-5-8. 